\title{
Gonococcal tysonitis
}

\author{
P.M. Abdul Gaffoor \\ Department of Dermatology, Hamad General Hospital, Doha, Qatar.
}

\begin{abstract}
Summary: A case of gonococcal urethritis with bilateral tysonitis is discussed. The patient was treated successfully with oral tetracycline $500 \mathrm{mg} 6$ hourly for 10 days, with a complete resolution.
\end{abstract}

\section{Introduction}

The incidence of sexually transmitted diseases is increasing throughout the world with a varied clinical spectrum of the diseases. Neisseria gonorrhoea which causes gonococcal urethritis shows a predilection for columnar epithelium.

Apart from the common problems of urethritis, proctitis and pharyngitis, gonococci can cause cutaneous lesions. Disseminated gonococcal infection follows mucosal infection with $N$. gonorrhoea (Mills \& Brooks, 1984). Skin lesions are an important clinical feature of this condition, characterized by erythematous papules which become pustular or haemorrhagic. The involvement of unusual sites may occur through the traumatized skin (Abdul Gaffoor, 1984), resulting from fellatio, teeth bites or by auto-inoculation from other infected sites.

Tyson's glands are sebaceous glands, without hair and with ducts lined by columnar epithelium, situated one on either side of the frenum. (Edward Tyson was an English physician and anatomist 1649-1708.) Involvement of Tyson's glands of the penis in gonorrhoea is not common and tysonitis is rarely mentioned in modern dermatology text books. Infection of Tyson's glands may occur separately or in conjunction with gonoccocal urethritis. Tysonitis presents a distinct and unique clinical picture which is easily diagnosed if there is awareness of the condition.

Infection of the Tyson's glands will result in tysonitis, causing a protruding cystic globoid enlargement either unilaterally or bilaterally. The cystic swelling is filled with pus and is tender.

\section{Case report}

An unmarried, heterosexual man attended the clinic complaining of a urethral discharge and painful

Correspondence: P.M. Abdul Gaffoor, M.B.B.S., Dip Ven, D.D.V., F.A.M.S.

Accepted: 20 February 1986 swelling of five days duration, near the glans penis. The patient had had sexual exposure six days before the onset of symptoms, with a casual partner. Examination revealed a purulant urethral discharge with globoid cystic fluctuant swellings about $1.5 \mathrm{~cm} \times 1 \mathrm{~cm}$ in size on either side of the frenum (Figure 1). Gram staining and culturing of the swabs from the urethral discharge and a bead of pus expressed from the swollen Tyson's glands proved to be $N$. gonorrhoeae. Repeated blood rapid plasma reagin tests were nonreactive. The patient had a history of penicillin hypersensitivity and was successfully treated with oral tetracycline $500 \mathrm{mg}$, every 6 hours for 10 days, with a complete resolution of the infection and cystic swelling. Follow up investigations for $N$. gonorrhoeae from the above sites were negative.

\section{Comments}

Gonococcal tysonitis is a rare entity and only a few cases have appeared in the literature. In 1976 Bavidge

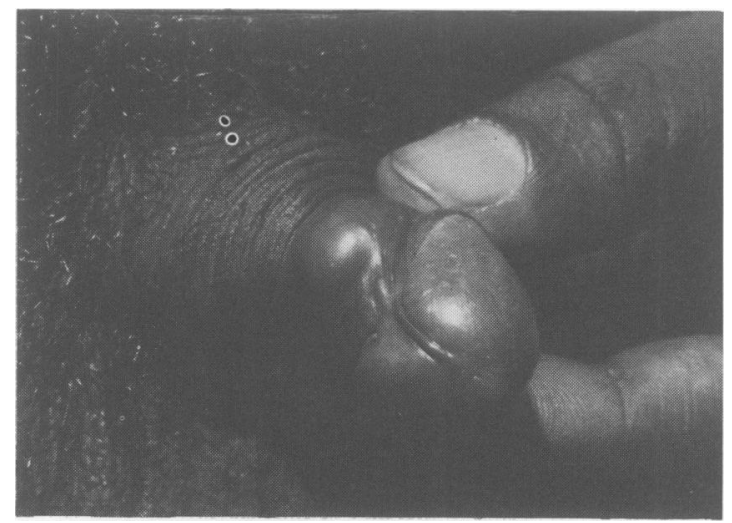

Figure 1 Globoid cystic swellings

The Fellowship of Postgraduate Medicine, 1986 
reported two cases of gonococcal tysonitis with urethritis and one case without urethritis. Fiumara (1977) reported a case of gonococcal tysonitis. Gonococcal urethritis with bilateral tysonitis and peri-urethral abscess also has been reported (Subramanian, 1981).

Needle aspirations or surgical drainage may be required in some cases for more rapid and complete resolution. Tysonitis can also be caused by organisms other than gonococci such as Escherichia coli. Of the

\section{References}

ABDUL GAFFOOR, P.M. (1984). Gonococcal cutaneous abscess. Medical Journal of Australia, 141, 902.

BAVIDGE, K.J.N. (1976). Gonococcal infections of the penis. British Journal of Venereal Diseases, 52, 66.

FIUMARA, N.J. (1977). Gonococcal tysonitis. British Journal of Venereal Diseases, 53, 145.

MILLS, J. \& BROOKS, G.F. (1984). Disseminated gonococcal infection. In Sexually Transmitted Diseases. Holmes, three tysonitis cases personally seen, two were due to gonococci and the third one was caused by E.coli, without any urethritis. The size of the swelling can vary from that of a large pea to that of a small olive (Morton, 1977). As there is more chance of infection in patients with congenital genital abnormalities and with phymosis, attention should be paid in such patients with gonorrhoea to rule out tysonitis or associated cutaneous involvement.

K.K., Mardh, P.A., Sparling, P.F. and Wiesner, P.J. (eds). p. 229. McGraw-Hill: New York.

MORTON, R.S. (1977). In Gonorrhoea. p. 82. W.B. Saunders: London.

SUBRAMANIAN, S. (1981). Gonococcal urethritis with bilateral tysonitis and periurethral abscess. Sexually Transmitted Diseases, 8, 77. 